\title{
Idiopathic calcinosis cutis of the right iliac region: Common lesion at uncommon site
}

\author{
Nidha Gaffoor ${ }^{1}$, Hima Sree Edupuganti ${ }^{1}$, Jessica Minal ${ }^{2}$, Archana Shetty ${ }^{2}$, Supriya T R ${ }^{1}$,Aparna Muralidhar ${ }^{3}$ \\ From ${ }^{1}$ Senior Resident, ${ }^{2}$ Associate Professor, ${ }^{3}$ Assistant Professor, Department of Pathology, Dr. Chandramma Dayananda Sagar Institute of Medical \\ Education and Research, Kanakapura, Karnataka, India
}

\begin{abstract}
Calcinosis cutis is an uncommon soft tissue lesion characterized by the deposition of calcium salts in the skin or subcutaneous tissue attributed to a wide variety of causes. We present a case of idiopathic calcinosis cutis in an adult male, who presented with a swelling in the right iliac region. Chalky white aspirate and amorphous basophilic granular material on microscopy suggestive of calcium deposits were noted. Histopathological examination of the excised mass coupled with appropriate clinical background led to the final diagnosis of idiopathic calcinosis cutis. We present this case with a complete diagnostic workup to undermine the importance of considering this lesion in the differential diagnoses of a subcutaneous hard lump in an otherwise healthy patient.
\end{abstract}

Key words: Calcinosis, Calcium, Fine-needle aspiration, Skin

$\mathrm{C}$ alcinosis cutis, first described by Virchow in 1855, is characterized by the deposition of calcium salts in the skin and subcutaneous tissue [1]. It develops due to the deposition of hydroxyapatite crystals of calcium phosphate and can involve any part of the skin [2]. Calcinosis cutis is classified into five major types according to the etiology-dystrophic, metastatic, iatrogenic, idiopathic, and calciphylaxis [3]. Family history, history of trauma, or injection, autoimmune screening, serum calcium, and phosphate levels, and location of calcium deposits are to be evaluated for the appropriate classification of a case [4]. Dystrophic calcinosis is a form of calcification that is associated with infection, inflammatory processes, cutaneous neoplasm, or connective tissue diseases. Metastatic calcification results from elevated serum levels of calcium or phosphorus. These calcifications occur as complications in patients with hyperparathyroidism and end-stage renal disease [3]. Iatrogenic and traumatic calcinosis are associated with medical procedures. Idiopathic calcinosis cutis is cutaneous calcification of unknown cause with normal serum calcium, no history of local tissue injury, or systemic metabolic disorder [5].

This is a case report of idiopathic calcinosis cutis diagnosed on fine-needle aspiration cytology (FNAC), further confirmed by histopathological examination. This study is aimed to cognize the presentation, etiopathogenesis, and the course of the relatively rare idiopathic calcinosis cutis and the possible confirmation of diagnosis by cyto-histomorphological study.

\section{Access this article online}

Received - 09 December 2021

Initial Review - 27 December 2021

Accepted - 30 December 2021

DOI: $10.32677 /$ ijcr.v7i12.3231

\section{CASE REPORT}

A 50-year-old man, bus driver by occupation presented to the surgical outpatient department with a painless swelling of size $7 \mathrm{~cm} \times 4 \mathrm{~cm}$ in the right hip region. The swelling had an insidious onset, was present for 2 years, and had gradually increased in size over the past 2 months. The patient had undergone an open appendicectomy 10 years ago with an uneventful hospital stay. There was no past history of trauma/injections/topical applications at the site of the swelling.

On examination, the swelling was nodular and firm in consistency, the overlying skin was pinchable and unremarkable (Fig. 1).

Chalky white amorphous material was aspirated on the FNA of the swelling (Fig. 2). Microscopy of the aspirate showed amorphous granular material staining basophilic on hematoxylin and eosin (H and E) and Papanicolaou (PAP) stain along with a few scattered histiocytes in the background (Fig. 3a and b). A cytological diagnosis of calcinosis cutis was conferred. Serum calcium and phosphate levels done preoperatively along with other routine hematological and biochemical investigations were within normal limits.

The swelling was excised and sent for histopathological examination. The gross specimen showed a skin-covered hard, irregular lesion measuring $8 \mathrm{~cm} \times 4 \mathrm{~cm} \times 2.5 \mathrm{~cm}$. On sectioning, the lesion was gritty with chalky-white calcified areas (Fig. 4a). Representative sections were taken and stained with $\mathrm{H}$ and $\mathrm{E}$ stain. Sections showed lobules of calcified material separated

Correspondence to: Dr. Jessica Minal, Department of Pathology, Dr. Chandramma Dayananda Sagar Institute of Medical Education and Research, Ramanagara, Kanakapura, Karnataka - 562 112, India. E-mail: jes.minal@gmail.com

(C) 2021 Creative Commons Attribution-NonCommercial 4.0 International License (CC BY-NC-ND 4.0). 


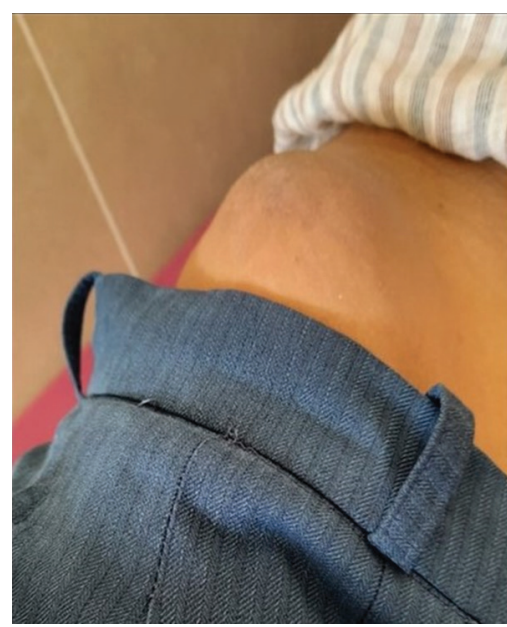

Figure 1: Swelling at the right hip joint

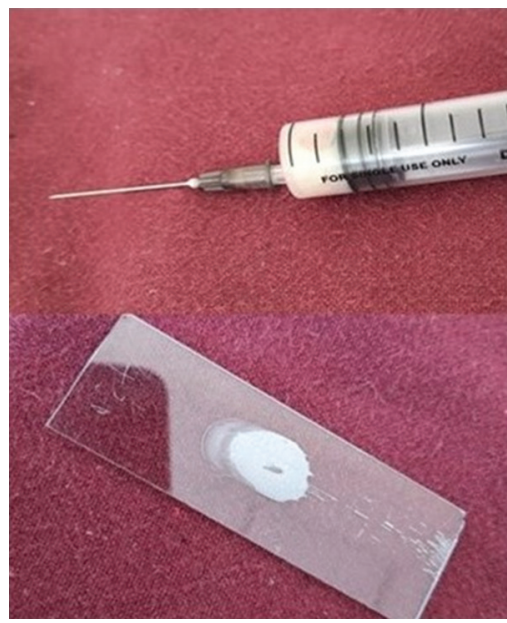

Figure 2: Upon fine-needle aspiration cytology, chalky-white material was aspirated

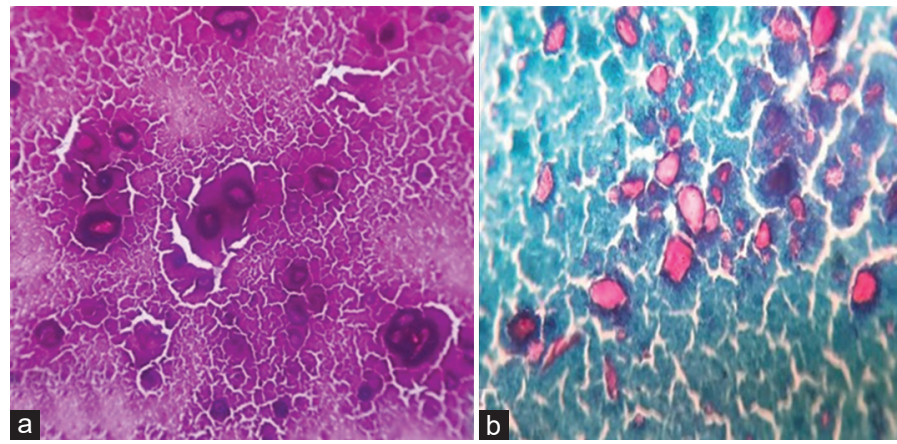

Figure 3: (a and b) Cytological smears showing amorphous granular material (H and E, PAP, $\times 100)$

by fibrous septa in the dermis with minimal inflammation. Occasional histiocytes were noted (Fig. 4b). A final diagnosis of calcinosis cutis/tumoral calcinosis was given.

\section{DISCUSSION}

Calcinosis cutis is a rare benign condition characterized by the deposition of calcium in the skin and subcutaneous tissue. Based on the pathogenesis, they are classified into five types: metastatic,

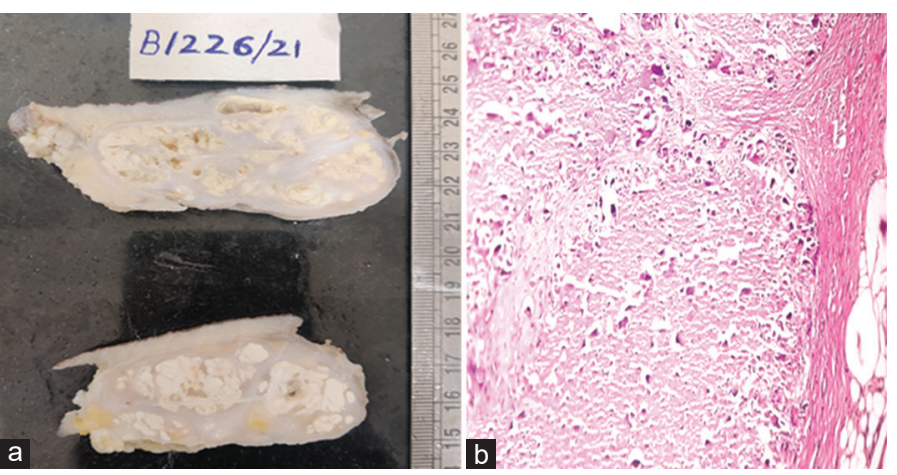

Figure 4: ( $a$ and b) Gross-chalky white gritty deposits, Microscopy-nests of calcified material separated by fibrous septa $(H$ and $E, \times 100)$

dystrophic, iatrogenic, idiopathic, and calciphylaxis [2]. Dystrophic calcinosis cutis and idiopathic calcinosis cutis are the most common and least common types, respectively.

The idiopathic type is characterized by subcutaneous deposition of calcium salts without underlying tissue damage or abnormal calcium or phosphorus levels [6]. It is a diagnosis of exclusion. Idiopathic calcinosis is further divided into three subtypes-tumoral calcinosis, sub-epidermal calcified nodules, and scrotal calcinosis. Tumoral calcinosis is a condition seen in healthy adolescents/adults, commonly presenting as subcutaneous or intramuscular masses around the major joints. The head and extremities are the commonly affected sites, where they are seen as solitary, hard, and whiteyellow nodules. This entity is associated with many autosomal recessive disorders and increased uptake of phosphate in the proximal tubule of the kidneys. Subepidermal calcified nodule (also called Winder nodular calcinosis) is usually observed in children and can be present at birth. Idiopathic scrotal calcinosis is an uncommon entity, first described by Lewinski in 1883. Though usually asymptomatic, it can present as scrotal nodules with or without pruritus or chalky white discharge [7-9]. Its pathogenesis is still unknown. Yoshida Sand, Lian et al. in their studies have suggested that de novo production of Gamma carboxyglutamic acid (GIa, an amino acid seen in proteins from calcified tissue) can lead to ectopic soft tissue calcification [10,11]. It has been noted that calcified tissue and urine of patients with scrotal calcinosis cutis showed elevated levels of GIa [2]. Among the above-mentioned subtypes, the case presented belongs to the tumoral calcinosis category.

When FNAC aspirates show abundant chalky white material, the differentials to be considered must include calcified fibrous pseudotumor, calcified epidermal cyst, sarcoidosis, tuberculosis, lymphoepithelial lesion, pilomatricoma, osteitis fibrosa cystica, and extraskeletal osteosarcoma. Calcified fibrous pseudotumor shows abundant hyalinized collagen, neurovascular bundles along with psammomatous calcification, and lymphoplasmacytic infiltrate. Calcified tuberculosis and sarcoidosis show a granulomatous reaction, whereas, calcified epidermal cyst shows anucleate and nucleate squames. Basaloid cells, ghost cells, and multinucleated giant cells are seen in pilomatricoma in addition to calcification. Lymphoepithelial lesions show lymphoid cells along 
with histiocytes and calcification. Extraskeletal osteosarcoma can be ruled out by careful clinical examination and the absence of any tumor cells in the sections [12]. Keeping in mind all the above differentials, we narrowed down to the diagnosis of calcinosis cutis in the above case.

Determining the exact type of calcinosis cutis is very important for accurate management. The patients should be evaluated for abnormalities of calcium and phosphorus metabolism and assessed for associated systemic conditions, such as collagen vascular diseases, renal insufficiency, and Vitamin D poisoning. Surgical excision is the treatment of choice for small calcified deposits and large localized lesions. This is not only curative but also allows for histopathological examination to confirm the diagnosis. For disseminated and extended disease, systemic therapy with warfarin, bisphosphonates, minocycline, intralesional corticosteroids, intravenous immunoglobulins, curettage, carbon dioxide laser, and extracorporeal shock wave lithotripsy is found to be beneficial $[6,12,13]$.

In the present case, serum calcium and phosphate levels were within normal limits. The patient had no history of trauma or topical injections at the site of the lesion. Other systemic illnesses were ruled out on evaluation. Hence, we categorized this lesion to be of idiopathic etiology.

\section{CONCLUSION}

Idiopathic calcinosis cutis is a benign condition, which mostly remains asymptomatic but can also present as a nodular mass. Cytological and histological findings in conjunction with serology and clinical evaluation help exclude the differentials and establish a conclusive diagnosis of this entity.

\section{REFERENCES}

1. Syed MA, Rajbhandari A, Paudel U. Idiopathic calcinosis cutis of the scrotum: A case report and review of the literature. J Med Case Rep 2018;12:1-5.

2. Choudhury M, Agarwal K, Singh S, Agarwal S. Cytodiagnosis of idiopathic calcinosis cutis: A case report. Turk Patoloji Derg 2015;31:145-7.

3. Sawke GK, Rai T, Sawke N. Iatrogenic calcinosis cutis: A rare cytological diagnosis. J Cytol 2016;33:166-8.

4. Binayke R, Taksande RV. Cytodiagnosis of idiopathic calcinosis cutis-a rare diagnosis in three cases with review of literature. Int J Health Sci Res 2017;7:1-6.

5. Arya A, Shelgaonkar G, Bhatti SS, Kumar D, Das P. Idiopathic calcinosis cutis in a young male: A cytological diagnosis with histopathological correlation. Indian J Pathol Microbiol 2020;63:140-1.

6. Alsaif F, Abduljabbar AM. Unilateral idiopathic calcinosis cutis: A case report. Case Rep Dermatol 2017;9:20-4.

7. Prabhu R, Sarma YS, Phillip K, Sadhu S. Diffuse idiopathic calcinosis cutis in an adult: A rare case. Eurasian J Med 2014;46:131-4.

8. Le C, Bedocs PM. Calcinosis cutis. In: StatPearls. Treasure Island, FL: StatPearls; 2021.

9. Jimenez-Gallo D, Ossorio-Garcia L, Linares-Barrios M. Calcinosis Cutis and Calciphylaxis. Actas Dermosifiliogr 2015;106:785-94.

10. Yoshida S, Torikari K. The effects of warfarin on calcinosis in a patient with systemic sclerosis. J Rheumatol 1993;20:1233-5.

11. Lian JB, Skinner M, Glimcher MJ, Gallop P. The presence of gammacarboxyglutamic acid in the proteins associated with ectopic calcification. Biochem Biophys Res Commun 1976;73:349-55.

12. Chide P, Mahadani J, Hingway S. FNAC of bilateral iliac idiopathic calcinosis cutis: A rare case report. J Cytol Histol 2016;7:436.

13. Róbert L, Kiss N, Medvecz M, Kuroli E, Sárdy M, Hidvégi B. Epidemiology and treatment of calcinosis cutis: 13 Years of experience. Indian J Dermatol 2020;65:105-11.

Funding: None; Conflicts of Interest: None Stated.

How to cite this article: Gaffoor N, Edupuganti HS, Minal J, Shetty A, Supriya TR, Muralidhar A. Idiopathic calcinosis cutis of the right iliac region: Common lesion at uncommon site. Indian $\mathrm{J}$ Case Reports. 2021;7(12):541-543. 